\title{
ANALISIS PERKEMBANGAN BAHASA BATAK MANDAILING PADA ANAK USIA 3 TAHUN 6 BULAN DITINJAU DARI SEGI SINTAKSIS
}

\author{
Oleh \\ Ummi Aisyah Siregar \\ NIM 8156192028 \\ ummiaisyahsiregar@gmail.com
}

\begin{abstract}
ABSTRAK
Tujuan dari penelitian ini adalah untuk mengetahui perkembangan bahasa batak mandailing anak, memberikan pengetahuan tentang perkembangan bahasa batak mandailing pada anak usia 3 tahun 6 bulan dan tentunya untuk menambah pengetahuan tentang perkembangan bahasa batak mandailing pada anak usia prasekolah. Untuk mendapatkan data bahasa batak mandailing usia anak 3 tahun 6 bulan ini digunakan metode simak (Sudaryanto, 1993), yakni pengumpulan data yang dilakukan dengan menyimak dan merekam penggunaan bahasa anak. Setiap hari saat siang hari sampai sore hari saan anak tersebut sedang sibuk bermain dilakukan pengamatan, perekaman, dan pencatatan atas bentuk-bentuk bahasa Indonesia usia anak 3 tahun 6 bulan tersebut. Aspek linguistik yang dianalisis dalam kajian ini ialah sintaksis. Analisis akan dilakukan secara kualitatif dan kuantitatif. Kaedah kuantitatif melibatkan analisis distribusi dan perkiraan $M L U$ sebagai satu kaedah menentukan perkembangan bahasa anak. Simpulan yang dapat dibuat berdasarkan dapatan analisis terhadap Raziq Ananda Rabbani yang berusia 3 tahun 6 bulan adalah analisis tuturan menunjukkan Raziq mempunyai $M L U$ 2,51 berada pada tahap rendah. Pada usia Tama tersebut seharunya $M L U$-nya berada pada tahan VIII yang $M L U$-nya antara 3,5-3,45. Jenis kata yang telah diperoleh dan dituturkan oleh Raziq antara lain nomina, verba, adjektiva, dan adverbia. Raziq telah mampu bertutur dari kalimat satu kata sampai kalimat lima kata yang berarti Raziq telah mampu bertutur kalimat lengkap. Raziq telah mampu bertutur membentuk pola kalimat dasar, seperti FN+FN, FN+FV, FN+FAdj, FN+FAdv.
\end{abstract}

Kata kunci: analisis, bahasa batak, dan sintaksis

\section{PENDAHULUAN}

Proses pemerolehan bahasa pada anak-anak merupakan satu hal yang perlu diteliti lebih mendalam. Bagaimana manusia memperoleh bahasa merupakan satu masalah yang amat mengagumkan dan sukar dibuktikan? Berbagai teori dari bidang disiplin yang berbeda telah dikemukakan oleh para pengkaji untuk menerangkan bagaimana proses ini berlaku dalam kalangan anak-anak. Memang diakui bahwa disadari ataupun tidak, sistem-sistem linguistik dikuasai dengan pantas oleh individu kanakkanak walaupun umumnya tidak dalam pengajaran formal. Pemerolehan bahasa merupakan satu proses perkembangan bahasa manusia. Ada dua proses yang terlibat 
dalam pemerolehan bahasa dalam kalangan anak, yaitu pemerolehan bahasa dan pembelajaran bahasa. Dua faktor utama yang sering dikaitkan dengan pemerolehan bahasa ialah faktor nurture dan faktor nature. Nature merupakan pemerolehan bahasa yang sudah ada sejak lahir sedangkan nurture merupakan pemerolehan bahasa yang dipengaruhi oleh lingkungan secara alami.

Bayi-bayi yang baru lahir sudah mulai mengenal bunyi-bunyi yang terdapat di sekitarnya. Brookes (dalam Yusoff, 1995:456) mengatakan bahwa pemerolehan bahasa dalam bentuk yang paling sederhana bagi setiap bayi bermula pada waktu bayi itu berumur lebih kurang 18 bulan dan mencapai bentuk yang hampir sempurna ketika berumur lebih kurang empat tahun. Menurut Simanjuntak (1982) pemerolehan bahasa bermaksud penguasaan bahasa oleh seseorang secara tidak langsung dan dikatakan aktif berlaku dalam kalangan anak-anak dalam lingkungan umur 2-6 tahun. Pemerolehan bahasa dikaitkan dengan penguasaan sesuatu bahasa tanpa disadari atau dipelajari secara langsung, yaitu tanpa melalui pendidikan secara formal untuk mempelajarinya. Pengkajian tentang pemerolehan bahasa sangat penting terutamanya dalam bidang pengajaran bahasa. Pengetahuan yang cukup tentang proses dan hakikat pemerolehan bahasa akan membantu menentukan keberhasilan dalam bidang pengajaran bahasa.

Pemerolehan bahasa pertama ialah bahasa yang pertama kali dikuasai oleh anak yang biasa disebut bahasa ibu. Setiap anak yang normal pada usia di bawah lima tahun dapat berkomunikasi dalam bahasa yang digunakan di lingkungannya, walaupun tanpa pembelajaran formal. Dalam usia ini pada umumnya anak-anak telah menguasai sistem fonologi, morfologi, sintaksis, dan semantik dari bahasa pertamanya. Penguasaan atau perkembangan bahasa anak diperoleh secara bertahap.

Salah satu perkembangan bahasa yang khas dialami anak adalah perkembangan sintaksis. Pada periode awal anak menggunakan kalimat satu kata, kalimat dua kata, kalimat tiga kata, dan seterusnya sampai tahap kalimat lengkap strukturnya (agentaction-object-location). Jumlah elemen yang mengandung arti dalam kalimat yang diucapkan anak dapat dapat diukur dengan Mean Length of Utterance (MLU). MLU merupakan satu konsep yang digunakan untuk mengukur produk linguistik yang dihasilkan oleh seseorang anak. Secara umum, penghitungan $M L U$ dilakukan dengan membagi bilangan morfem dengan bilangan ujaran. Artinya, jumlah bilangan ujaran 
yang diperlukan ialah 50 atau 100 ujaran utama anak. Semakin tinggi $M L U$ anak maka semakin tinggilah penguasaan berbahasa anak tersebut. Manfaat penelitian ini adalah untuk mengetahui perkembangan bahasa awal pada anak usia 3 tahun 6 bulan, mengetahui perkembangan bahasa anak yang mencangkup kata dan kalimat, mengerti tahapan perkembangan bahasa pada anak usia 3 tahun 6 bulan.

\section{METODOLOGI PENELITIAN}

Sumber data penelitian ini adalah anak laki-laki usia 3 tahun 6 bulan. Anak tersebut bernama Raziq Ananda Rabbani. Sehari-hari anak tersebut tinggal di asrama bersama orang tuanya dan sering bermain dengan teman-teman yang seusianya juga ada teman-teman yang di atas usianya. Anak tersebut sering ikut kegiatan orang tuanya, misalkan senam, arisan dan perwiritan.

Data penelitian dikumpulkan melalui hasil rekaman tuturan anak dengan orang tuanya maupun dengan teman-teman yang seusianya dan di atas usianya. Alat yang digunakan untuk merekam adalah hanphone. Data yang dikumpulkan hanyalah sebanyak 100 tuturan anak yang diambil sebagai sampel untuk mengukur $M L U$ anak tersebut. Data diambil dari tanggal 03 Juni - 06 Juni 2016. Lokasi perekaman ada tiga yaitu dirumah, taman bermain dan di rumah neneknya. Data diambil saat siang hari sampai sore hari saat si anak sedang sibuk bermain dan yang terlibat pada saat perekaman adalah orang tuanya, neneknya dan teman-temannya.

Fokus penelitian ini adalah bahasa batak mandailing anak usia 3 tahun 6 bulan yang terjadi secara alamiah. Penelitian ini dirancang dengan desain penelitian survei. Surakhmad (1982 : 139) menyebut desain penelitian survei ini dengan metode deskriptif.

Penelitian ini menggunakan pendekatan kualitatif. Penelitian kualitatif terfokus pada fenomena yang dikaji. Berdasarkan pandangan ini, lokasi penelitian dipilih berdasarkan pertimbangan kadar kealamiahan pemakaian bahasa Indonesia anak-anak, yakni di rumah, taman bermain dan di rumah neneknya. Penetapan lokasi penelitian di atas didasari oleh kondisi empirik penggunaan bahasa Indonesia. Di tempat itulah sang anak telah menggunakan bahasa Indonesia secara alamiah dalam melaksanakan aktivitas sehari-hari.

Penelitian ini menggunakan data primer. Dalam penelitian ini, data diambil dari penggunaan bahasa Indonesia anak usia 3 tahun 6 bulan. Data yang dikumpulkan berupa 
ujaran bahasa Indonesia anak. Data primer yang terkumpul dipilah menjadi dua, yaitu data emik dan data etik. Data emik adalah data yang secara signifikan bermakna bagi para anggota komunitas yang dikaji, sedangkan data yang tidak bermakna dan hanya sebagai variasi disebut data etik (Gunarwan, 2002 : 20). Dalam penelitian ini, data etik tidak dianalisis.

Sumber data penelitian ini adalah bahasa batak mandailing yang diproduksi oleh anak usia 3 tahun 6 bulan. Periode usia ini merupakan masa dinamis perkembangan bahasa pada anak-anak (Crider, 1983; Subyakto-Nababan, 1988; Oesterreich, 1999, Dardjowidjojo, 2003). Subjek penelitian ini ditetapkan hanya seorang saja yaitu anak yang berusia 3 tahun 6 bulan.

Untuk mendapatkan data bahasa batak mandailing usia anak 3 tahun 6 bulan ini digunakan metode simak (Sudaryanto, 1993), yakni pengumpulan data yang dilakukan dengan menyimak dan merekam penggunaan bahasa anak. Setiap hari saat siang hari sampai sore hari saan anak tersebut sedang sibuk bermain dilakukan pengamatan, perekaman, dan pencatatan atas bentuk-bentuk bahasa Indonesia usia anak 3 tahun 6 bulan tersebut. Pengamatan berkala dilakukan selama satu minggu penuh sehingga setiap lokasi penelitian diamati sebanyak 3 kali. Setiap pengamatan berlangsung antara $90-120$ menit.

Aspek linguistik yang dianalisis dalam kajian ini ialah sintaksis. Analisis akan dilakukan secara kualitatif dan kuantitatif. Kaedah kuantitatif melibatkan analisis distribusi dan perkiraan $M L U$ sebagai satu kaedah menentukan perkembangan bahasa anak tersebut. Penganalisisan data dapat dilakukan dengan empat langkah, yaitu: (1) Pentranskripsian Data adalah tuturan yang direkam melalui handphone ditranskrisikan dalam bentuk kalimat. Data yang terkumpul tersebut disusun dalam bentuk stuktur kalimat tuturan anak. (2) Penyeleksian Data adalah data yang telah ditransipsikan diolah dengan memisahkan data yang dibutuhkan dan memenuhi syarat yang sesuai dengan tujuan penelitian. tuturan anak yang diseleksi adalah tuturan yang memenuhi syarat untuk dihitung $M L U$-nya. (3) Pengklasifikasian Data adalah data yang telah diseleksi sesuai dengan tujuan penelitian dan data yang dapat dihitung $M L U$-nya. Cara mengklasifikasikan data tersebut adalah dengan mengelompokkan tuturan anak berdasarkan jumlah morfem setiap tuturan. Selanjutnya, jumlah morfem setiap tuturan dijumlahkan (jumlah ujaran dibatasi hanya sampai 100 ujaran). Kemudian, jumlah morfem dari 100 tuturan tersebut dibagi dengan 100. (4) Pemaparan Hasil Analisis Data adalah setelah diketahui hasil $M L U$, hasil tersebut dianalisis untuk mengetahui anak yang 
menjadi sampel penelitian berarada pada tahap apa dan menganalisis pemerolehan sintaksis dari segi panjang tuturan dan struktur sintaksis. Struktur sintaksis seperti jenis kata yang telah diperoleh dan pola kalimat diperoleh.

\section{HASIL PENELITIAN DAN PEMBAHASAN}

\section{Hasil Penelitian}

Hasil rekaman tuturan anak yang telah ditranskripsikan ke ejaan fonetik yang diartikan ke dalam bahasa Indonesia.

1. Kalimat Satu Kata

Nda 'tidak'

Indak... 'tidak...'

Madung 'sudah'

Olo 'iya'

Mua? 'sedang apa?'

Aha? 'apa'

Ndak 'tidak'

haloo 'halo'

Pedo 'belum'

Lo 'iya'

Mate 'mati'

Umak 'ibu'

Mangan 'makan'

Pat Le..' 'cepatlah'

Cepat leng 'cepatlah'

Kakkak 'kakak'

Aha? 'apa?'

Ro 'datang'

Suk 'busuk'

Lo. 'Тya'

Wat Le 'ambillah'

Locok. Malas'

2. Kalimat Dua Kata 
Ulangi buce 'ulang lagi'

Bisa dei 'bisa itu'

Nda mak 'tidak ibu'

Anggik cayang 'adek sayang'

Dedek ibuk 'adek ibu'

Dio roti? 'mau roti'

Magecet kakak 'kakak bicara'

Inda Uboto 'tidak tau'

Dung maridi 'sudah mandi'

Get mua? 'mau apa?'

Sappuluh libu 'sepuluh ribu'

Cocak dinding 'cicak di dinding'

Sada sada 'satu satu'

Cocak-cocak malayap 'cicak-cicak merayap'

Кири-kири siapor 'kupu-kupu bilalang'

Dung mate 'sudah mati'

Kehe raon-raon 'pergi jalan-jalan'

Umak inan? 'ibu itu'

Umak kakak 'ibu kakak'

Umak inan? 'ibu itu'

Na menek.! 'Yang kecil!'

Manyogot i. 'tadi pagi'

3. Kalimat Tiga Kata

Din anggi uda 'itu adek Om'

Nenen umak mah? 'susu ibu mah?'

Bahat botik $i$ 'banyak papaya itu'

Jau botik $i$ 'mau papaya itu!'

Pake daging $i$ 'ada pakai daging'

Anggik sayang abang 'adek sayang abang'

Inda dong $i$ 'tidak ada itu'

Kehe ia raun-raun 'dia pergi jalan-jalan'

Aso abang tiop 'biar kakak pegangnya' 
Uda kehe rauraun 'Om pergi jalan-jalan'

Kawan pette jolo 'tunggu dulu teman'

Mangecet rap umak 'bicara sama ibu'

Bayar pakil kan! 'bayar parkir ya!'

Bau ia 'dia busuk sekali'

Abang bukon da 'kakak buang ya'

Dung mangollu ia 'sudah hidup dia'

Dot umak soni 'sama ibu saja'

Abang sipak anggi 'abang tendang adek?'

Abang palua kakak lepas ini!'

Bagas ni nenek 'rumah nenek'

Umak manaek kleta 'ibu naik sepeda motor'

Abang pio ia 'Abang panggil dia'

Abang lagi mamua? 'abang, sedang apa?'

Aha dokkon ia mak? 'Apa katanya bu?'

Ia aha dei.? 'Dia apa itu?'

Aha on mak? 'apa ini bu?

Aha indun mak? 'apa itu bu?

Nda tola lana? 'tidak boleh ya'

Matcit tangan umak? 'ibu tangannya sakit'

Baca doa jolo. 'baca doa dulu

4. Kalimat Empat Kata

Abang salgut hp on 'kakak gigit hp ini!'

Mak ulangi buse , mak! 'Bu ulang lagi, Bu?'

Madung kehe nenek nakkin 'nenek tadi sudah pergi'

$N d a$ dong alak na $i$ 'tidak ada orangnya itu'

Cepat le diau botik 'cepatlah mau pepaya'

Cepat le suara aha $i$ 'cepatlah bunyi-bunyian itu'

Ulangi muse mak e, ulang lagi $\mathrm{Bu}$ '

Nda dong ia mate 'tidak ada dia mati'

Mak ulangi mak e 'bu ulang lagi bu?'

Tokkin nai ita kehe. Nanti kita pergi ya?' 
Aha dokkon ia? 'apa katanya itu?'

Get di umak namenek. 'Untuk ibu yang kecil'

Inda giot kakak be. 'Tidak mau kakak lagi.'

Nda maen hp ne. 'Tidak main hp tidak'

\section{Kalimat Lima Kata}

Uda madung kehe mak e? 'om sudah pergi ya bu'

Inda dong ia mate da 'tidak ada dia mati itu'

Pake baju baru kin ba' pake baju baru tadi'

Umak adond kaset cocak-cocak'Bu ada kaset cicak-cicak’

Di buat ia motor-motor ade. 'dia dia aambil mobil-mobilan adek'

Madung boto umak goar nia nakkin? 'ibu sudah tahu nama dia?'

Di umak na menek jolo. 'Untuk ibu yang kecil dulu'

Pake badak abang so ganteng 'pake bedak abang biar tampan.'

\section{Pembahasan Hasil Penelitian}

Tabel 1 Analisis Panjang Tuturan

\begin{tabular}{|l|l|l|}
\hline \multicolumn{1}{|c|}{ Jumlah Kata Per Tuturan } & Jumlah Tuturan & Jumlah Morfem \\
\hline Kalimat satu kata & 26 & 26 \\
\hline Kalimat dua kata & 25 & 50 \\
\hline Kalimat tiga kata & 28 & 84 \\
\hline Kalimat empat kata & 14 & 56 \\
\hline Kalimat lima kata & 7 & 35 \\
\hline Total & 100 & 251 \\
\hline
\end{tabular}

$$
\begin{aligned}
M L U & =\frac{\text { Jumlah morfem }}{\text { Jumlah tuturan }} \\
& =\frac{251}{100}=\mathbf{2 , 5 1}
\end{aligned}
$$

Berdasarkan hasil pengukuran $M L U$ di atas, panjang tuturan Raziq Ananda Rabbani 2,51 kata pertuturan. Bila disesuaikan dengan pendapat Brown, Raziq masih pada tahap $\mathrm{V}$ yang berarti pemerolehan bahasa masih rendah karena pada usia Raziq 
sekarang seharusnya $M L U$ berada pada tahap VIII, yaitu $M L U$ berkisar antara 3,5-3,45 kata pertuturan.

Berdasarkan data yang diperoleh dan dikelompokkan, Raziq telah mampu bertutur dari kalimat satu kata sampai kalimat lima kata. Jenis kata yang sudah dikenal Raziq adalah nomina (N), verba (V), Adjektiva (Adj), Adverbia (Adv)

N 'tangan', cocak 'cicak', umak 'ibu'

V kehe raun-raun 'pergi jalan-jalan'

Adj bucuk 'busuk', malosok 'malas'

Adv Cocak di dinding 'cicak di dinding'

Bila dilihat dari pola kalimat, Tama telah mampu bertutur dengan pola dengan pola dasar seperti FN+FN, FN+FV, FN+FAdj, FN+Adv.

FN+FN abang palua on 'abang lepas ini'

$\mathrm{FN}+\mathrm{FV} \quad$ mangecet abang'abang bicara'

FN+FAdj Anggi sayang 'adek sayang'

FN+Adv Cocak dinding 'cicak di dinding

\section{PENUTUP}

Simpulan yang dapat dibuat berdasarkan dapatan analisis terhadap Raziq Ananda Rabbani yang berusia 3 tahun 6 bulan adalah sebagai berikut.

1. Analisis tuturan menunjukkan Raziq mempunyai $M L U 2,51$ berada pada tahap $\mathrm{V}$ yang berarti berada pada tahap rendah. Pada usia Tama tersebut seharunya $M L U$ nya berada pada tahan VIII yang $M L U$-nya antara 3,5-3,45.

2. Jenis kata yang telah diperoleh dan dituturkan oleh Raziq antara lain nomina, verba, adjektiva, dan adverbia.

3. Raziq telah mampu bertutur dari kalimat satu kata sampai kalimat lima kata yang berarti Tama telah mampu bertutur kalimat lengkap. 
Raziq telah mampu bertutur membentuk pola kalimat dasar, seperti $\mathrm{FN}+\mathrm{FN}, \mathrm{FN}+\mathrm{FV}$, FN+FAdj, FN+FAdv. Orang tua dan keluarga sebagai orang terdekat dengan Raziq sebaiknya terus melatihnya untuk berbicara dengan baik, baik dalam konteks bahasa ibunya maupun dalam konteks bahasa Indonesia.

\section{DAFTAR PUSTAKA}

Darjowodjojo, Soenjono. 2010. Psikolinguistik: Pengatar Pemahaman Bahasa Manusia. Jakarta: Yayasan Obor Indonesia.

Nababan dan Sri Utari Subyakto. 1992. Psikolinguistik: Suatu Pengatar. Jakarta: Gramedia Pustaka Utama.

Owens, J.E. 2008. Excerpt from Language Development: An Introduction. Dalam http://www.education.com/reference/article/acquisition-sentence-form. Diakses tanggal 03 Juni 2016

Simanjuntak, Mangantar. 1982. Pemerolehan Bahasa Melayu: Bahagian Fonologi. Jurnal Dewan Bahasa, Ogos/September, 615-625.

Yusoff, Abdullah dan Che Rabiah Mohamed (1995). Teori Pemelajaran Sosial dan Pemerolehan Bahasa Pertama. Jurnal Dewan Bahasa, Mei. 456-464.

Itadz (2008) Memilih, Menyusun dan Menyajikan Cerita untuk Anak Usia dini, Yogyakarta:

Tiara Wacana

Dardjowidjojo, Soenjono. 2000. ECHA. Kisah Pemerolehan Bahasa Anak. Jakarta: Grasindo

Hasan Alwi, dkk., Tata Bahasa Baku Baku Bahasa Indonesia (Jakarta: Balai Pustaka, 2003), hlm. 311.

Daulay, Syahnan. 2012. Pemerolehan dan Pembelajaran bahasa. Bandung: Citapustaka Media Perintis. 